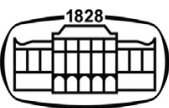

AKADÉMIAI KIADÓ

\title{
Application of viscoelastic dampers for reducing dynamic response of high-speed railway bridges
}

\section{International Review of Applied Sciences and Engineering}

$11(2020)$ 2, 95-106

DOI:

$10.1556 / 1848.2020 .20004$

(c) 2020 The Authors

\section{ORIGINAL RESEARCH PAPER}

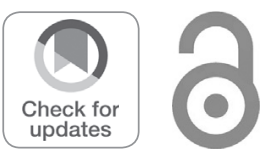

*Corresponding author.

E-mail: tamamed7@gmail.com

\author{
MOHAMED TAHIRI ${ }^{1 *}$, ABDELLATIF KHAMLICHI $^{2}$ and \\ MOHAMMED BEZZAZI ${ }^{1}$ \\ ${ }^{1}$ Department of Physics, Mechanical and Civil Engineering Laboratory, Faculty of Sciences and \\ Technology, University Abdelmalek Essaadi, Tangier, Morocco \\ ${ }^{2}$ Department STIC, Communication Systems and Detection Laboratory, National School of Applied \\ Sciences, University Abdelmalek Essaadi, Tetouan, Morocco
}

Received: June 7, 2019 • Accepted: November 20, 2019

Published online: July 23, 2020

\section{KEYWORDS}

high-speed railway bridges, fractional derivative, viscoelastic dampers, energy, vibration control, resonance

\section{INTRODUCTION}

Since the development of high-speed railway lines, the railway infrastructure and in particular bridges require continuous upgrading. During the passage of the train across the railway bridge, resonance takes place when the frequency of the periodic loading of the train comes close to the natural frequency of the bridge. In this case, high levels of the vertical acceleration of the bridge are yielded, which can produce adverse consequences such as passenger discomfort, risk of derailment, and fatigue damage. To attenuate the level of this acceleration, classical solutions may be used, such as increasing the damping of the bridge or increasing its stiffness. In these circumstances, the bridge deck is damped or stiffened in order to keep the vertical acceleration below the serviceability limit state of $3.5 \mathrm{~m} / \mathrm{s}^{2}$ for ballasted tracks and $5 \mathrm{~m} / \mathrm{s}^{2}$ for direct unballasted tracks [1]. Kwon et al. [2] and Wang et al. [3] investigated the application of Tuned Mass Dampers (TMDs) in order to absorb the dynamic response of the bridge. Luu et al. [4] investigated an $\mathrm{H}_{2}$ optimization method to study the efficiency of installing the TMDs in order to suppress the multi resonant response of the bridge. Samani and Pellicano [5] have compared the efficiency of the linear and nonlinear TMDs connected to simply supported beam under moving loads. On the other hand, another device such as the application of fluid viscous dampers (FVDs) has been addressed by many authors such as Museros and Martinez Rodrigo 
[6-8], who investigated a planar model that consists of simply supported auxiliary beam connected to the main beam and the main plate by a set of linear FVDs. Luu et al. [9] demonstrated the efficiency of the $H_{\infty}$ optimization method of a planar model which consists of the main beam connected to an auxiliary beam by linear FVDs and investigated the effect of nonlinearity on the dynamic response. Lavado et al. [10] investigated the same model by connecting the main beam to an auxiliary beam clamped between the bridge abutments by a set of linear FVDs. Raderstrom et al. [11] investigated a new planar model by installing inclined FVDs between the bridge deck and the abutment in order to absorb the vibrations oscillations of the bridge under resonance conditions. Metin et al. [12] investigated the same model of Raderstrom by installing inclined semi-active magnetorheological dampers for reducing the dynamic response.

In this work, focus is on the particular solution which consists of increasing the damping ratio by using passive energy dissipation generated by ViscoElastic Dampers (VEDs) in order to limit bridge vertical acceleration. The first big application of VEDs to improve the dynamic performance of structures was achieved in 1969 when they were used for reducing wind-induced vibrations of the World Trade Center in New York by installing approximately 10,000 VEDs in each of the twin towers [13]. Choo et al. [14] proposed the retrofit of long-span bridges by installing viscoelastic materials, and the results showed good agreements between the proposed model and the experiments. The authors concluded that the proposed solution could reduce the dynamic response of longspan bridges. Moliner et al. [15-16] investigated the efficiency of the installation of VEDs for reducing the resonant response of a short simply supported railway bridge. Tsai and Lee [17] developed a finite element model based on fractional derivatives in order to study the performance of viscoelastic materials in attenuating the dynamic response of a building under seismic loading.

VEDs are now one of the most widely used passive energy dissipation devices. Viscoelastic material dissipates energy through shear deformation, which is generally described by two main parameters; the shear storage modulus $G_{E}$ and the loss factor $\eta$. These important properties of viscoelastic materials depend on the strain ratio, excitation frequency, and temperature [18-19]. A large number of models were proposed for describing the behavior of VEDs. The classical models use a combination of springs and dashpots elements, such as Kelvin-Voigt model or Maxwell model which are linear. The predominant model existing nowadays is nonlinear and uses the fractional derivatives concept. Lewandowski and Pawlak [20] investigated the fractional derivatives model by using the continuation method to solve the nonlinear eigenvalue problem. To overcome numerical difficulties resulting from nonlinearity, equivalent linear VEDs were introduced through linearization as indicated in [21].

In the present study, the linearization methodology of the fractional derivatives model is used. A planar model of the bridge is considered, and VEDs are assumed to be mounted directly between the abutments and the bottom surface of the bridge deck without interposing any auxiliary beam. The VEDs are given an inclination in order to profit from the eccentricity appearing between the fixation point on the bridge and the beam neutral axis. For the frequencies intervening in the problem, only the first mode of the bridge according to Eurocode 1 [1] is needed. The mechanical system can then be described by a Single Degree of Freedom (SDOF) oscillator excited by repetitive loads resulting from train circulation as defined by Eurocode 1. The effect of VEDs on the dynamics of bridge beam under the action of train loading is then integrate, through their linear equivalent model. The obtained equation is solved analytically. Subsequently, this analytical model is used to evaluate the performance of the VEDs on the dynamic response of two bridges having different lengths that were studied in literature and which were damped by systems using an auxiliary beam that serves to mount the dampers vertically. A parametric study is conducted to optimize VEDs orientation and to determine the damping system characteristics that are required to meet Eurocode 1 recommendations. Other effects such as temperature and the shear area of dampers are analyzed. Finally, the efficiency of the proposed damping system is discussed.

\section{MATERIALS AND METHODS}

\subsection{Planar retrofitting model}

The configuration of damping system presented here is similar to that proposed in a previous work performed by Raderstrom et al. [11]. The difference comes from the fact that VEDs are used here instead of FVDs. Contrary to the FVDs, the VEDs have some stiffness and the effect of this stiffness on the bridge behavior should be accounted for. Moliner et al. [16] have studied the effect of VEDs modeled by fractional derivatives on the dynamic response of short high-speed railway bridge when connecting the main beam to an auxiliary beam by a set of VEDs that were mounted vertically. In this work, the damping system is different in that inclined VEDs are used. They are installed directly between the bottom surface of the bridge deck and abutments. This configuration does not use any auxiliary beam as for instance are used in Ref. $[9,16]$. It enables to take into account the effect of eccentricity between the neutral axis of the bridge beam and the contact point of the VEDs with the bottom surface of the bridge deck [11]. Axial force of damping as well as vertical force of damping is then present in the system.

This system is convenient, especially in order to perform retrofitting of existing railways bridges to allow them to accommodate for new train circulation loads or higher speeds. Fig. 1 shows the planar model of the proposed dissipative system which is intended to attenuate the vibrations appearing in a single track railway bridge. The bridge system is modeled by a simply supported Euler-Bernoulli (EB) beam. As the abutments and the slab are rigid, the local deformation at the dampers connections with the abutments 


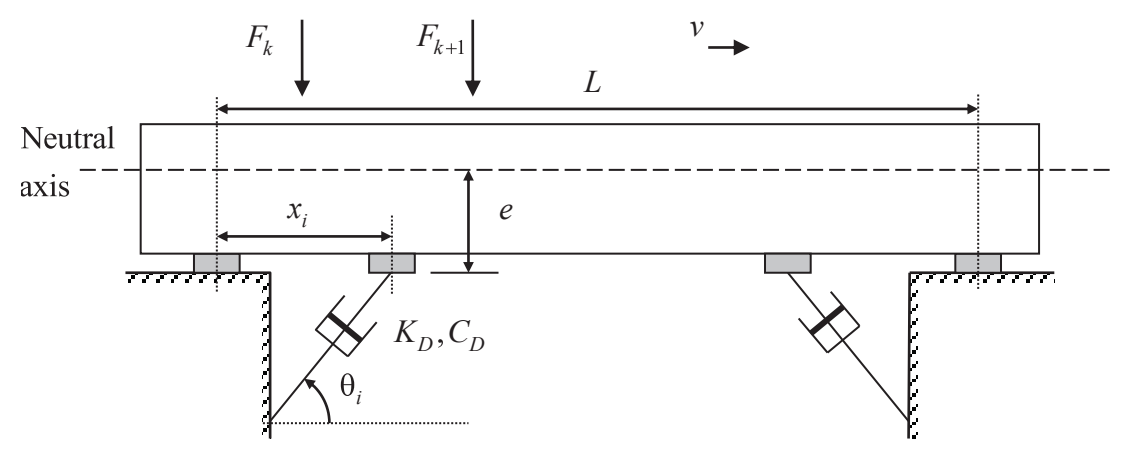

Fig. 1. Simple supported bridge beam connected by means of inclined VEDs to abutments

and the slab can be neglected. The E-B beam is connected with the abutments without any elastic bearing. The bridge system dynamics is considered under the action of a moving train loading. In the literature, this kind of excitation was simulated by using three different approaches: the moving load model, the moving mass model, and the moving sprung mass. However, in common applications, it was shown that the relative difference resulting from using either one of these models is limited to about $2.5 \%$ near the resonance frequencies. Furthermore, the vehicle bridge interaction leads to a reduction in the dynamic response of the bridge. For these reasons, constant-valued moving loads representing a circulating train are assumed below. The sequence of these loads is defined according to Eurocode 1 [1].

Generally, for a single track, non-skewed bridge, torsional vibrations of the beam resulting from eccentric moving loads are neglected, so only the first bending modes of vibration are to be taken into account. A criterion of Eurocode 1 expressed in terms of frequency yields that in almost all practical cases, only the first mode of flexural vibration is to be retained and the bridge can be assumed to be a SDOF system.

The VEDs considered in this work are modeled by using the concept of fractional shear stress relationship, which according to [17] is written as:

$$
\tau(t)=G_{E} \varepsilon(t)+G_{C} D^{\alpha}[\varepsilon(t)]
$$

where $\tau(t)$ and $\varepsilon(t)$ are the shear stress and shear strain of the VED; $G_{C}, G_{E}$ are the two constitutive model parameters and the terms $D^{\alpha}[\varepsilon(t)]$ is the Riemann-Liouville fractional derivative which is defined as follows:

$$
b D^{\alpha}[\varepsilon(t)]=\frac{1}{\Gamma(1-\alpha)} \frac{d}{d t} \int_{0}^{t} \frac{\varepsilon(\zeta)}{(t-\zeta)^{\alpha}} d \zeta
$$

in which $\Gamma($.$) is the gamma function and 0<\alpha<1$. The constitutive model parameters are given by

$$
G_{E}=A_{0}\left\{1+\mu e^{\left.-\beta\left[\int \tau d \varepsilon+v\left(T-T_{0}\right)\right]\right]}\right\} \text { and } G_{C}=\eta G_{E}
$$

where $\eta$ is the loss factor of the viscoelastic material, $T$ the ambient temperature, $T_{0}$ the reference temperature, $A_{0}, \alpha, \beta$, $\mu$ and $v$ are coefficients of the viscoelastic dampers that are to be determined experimentally.

In this work, the same coefficients $A_{0}, \alpha, \beta, \mu$ and $v$ are used as those given in [16].

\subsection{Governing equation of the single degree of freedom system}

Several authors have presented the partial differential equation governing the flexural behavior of a simply supported beam subjected to moving load, with taking into account the $N$ modes contributions. The system of equations of the retrofitting system, which is valid for the nonlinear VEDs, has been shown to have the following form when written in modal coordinates [16]:

$$
\begin{aligned}
& M \ddot{q}(t)+C \dot{q}(t)+K q(t)+P^{T} K_{D} P q(t)+P^{T} C_{D} P D^{\alpha}[q(t)] \\
& \quad=F(t)
\end{aligned}
$$

with

$$
q(t)=\left[\begin{array}{llll}
q_{1} & q_{2} & \cdots & q_{N}
\end{array}\right]^{T}
$$

and

$$
\begin{aligned}
M & =\left[M_{i i}\right]=\frac{m L}{2}, C=\left[C_{i i}\right]=\xi_{i} \omega_{i} m L, K=\left[K_{i i}\right] \\
& =\left(\omega_{i}\right)^{2} \frac{m L}{2}, i=1,2, \ldots, N
\end{aligned}
$$

where $N$ is the total number of equations which is equal to the number of retained contribution modes to the response of the beam, $q$ is the column vector of modal displacements, $M$ is the mass matrix, $C$ is the damping matrix, $K$ is the stiffness matrix, $m$ is the mass per unit length, $L$ is the length of the beam, $\omega_{i}$ stands for modal frequency, and $\xi_{i}$ for damping coefficient. The matrices $\mathrm{M}, \mathrm{K}$, and $\mathrm{C}$ are given in modal coordinates and are diagonal because structural damping is assumed to be modal, while the last two terms in the first half of Eq. (4) are not necessarily diagonal.

In Eq. (4), $P$ is a matrix which transforms the modal coordinates $q(t)$ into elongations of the dampers. It has the following form 


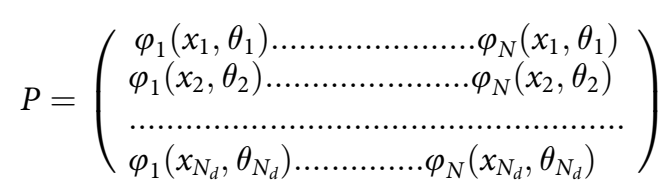

where $N_{d}$ is the number of dampers installed as the retrofitting system, $x_{1}, x_{2}, \ldots, x_{N_{d}}$ and $\theta_{1}, \theta_{2}, \ldots, \theta_{N_{d}}$ are the locations and the orientation angles measured from the horizontal for each of the VEDs.

As mentioned in [11], $\varphi_{i} i=1, \ldots, N$ are the modal coordinates of dampers which are given by

$$
\begin{aligned}
& \varphi_{i}\left(x_{j}, \theta_{j}\right)=\frac{i \pi e}{L} \cos \left(\theta_{j}\right) \cos \left(\frac{i \pi x_{j}}{L}\right)+\sin \left(\theta_{j}\right) \sin \left(\frac{i \pi x_{j}}{L}\right) \\
& \quad j=1,2, \ldots, N_{d}
\end{aligned}
$$

where $e$ defines the eccentricity between the neutral axis of the bridge beam and the fixation point of the VED at the bottom surface of the bridge, see Fig. 1.

In Eq. (4), $K_{D}$ and $C_{D}$ contain the VED terms of the fractional model and have the following form [16]:

$$
K_{D}=\left[\begin{array}{ccc}
k_{D}^{1} & 0 & 0 \\
0 & \ddots & 0 \\
0 & 0 & k_{D}^{N_{d}}
\end{array}\right], C_{D}=\left[\begin{array}{ccc}
c_{D}^{1} & 0 & 0 \\
0 & \ddots & 0 \\
0 & 0 & c_{D}^{N_{d}}
\end{array}\right]
$$

with $k_{D}=\frac{G_{E} A}{h_{V E D}}, c_{D}=\frac{G_{C} A}{h_{V E D} \omega_{b}}$ in which $\omega_{b}=\left(\frac{\pi}{L}\right)^{2} \sqrt{\frac{E I}{m}}$ and where $A$ is the shear area of damper, $h_{V E D}$ is the shear thickness of the VEDs, $E$ is the Young's modulus, and $I$ the moment of inertia of beam section.

Finally, the second half term in Eq. (4) constitutes the vector of moving modal forces. It has the explicit following form [16]

$$
\begin{aligned}
F(t)= & \sum_{k=1}^{N_{v}} F_{k}\left[H\left(t-t_{k}\right)\right. \\
& \left.-H\left(t-t_{k}-\frac{L}{v}\right)\right]\left(\Phi_{1}\left(v t-x_{k}\right) \ldots \Phi_{N}\left(v t-x_{k}\right)\right)^{T}
\end{aligned}
$$

where $\Phi_{i}(x)=\sin \left(\frac{i \pi x}{L}\right)$ is a mode shape of vibration of the simply supported beam, $x_{k}=(k-1) D$ the initial distance from the k-th load to the origin of the beam, $\mathrm{D}$ the coach length, $N_{v}$ is the total number of axle loads, $F_{k}$ is the value of the kth load and $H(t-a)$ is the Heaviside unit function acting at time $a$.

It can be seen that Eq. (4) is a nonlinear-coupled equation because of the viscoelastic dampers terms appearing in the first half. However, only the first mode will be retained here as the higher frequencies exceed the limit of $30 \mathrm{~Hz}$ as stated by Eurocode [1]. Thus, only one scalar equation is considered and the bridge model reduces to a SDOF system. The obtained nonlinear equation can be solved by using different numerical methods. In particular, by performing linearization of the last viscoelastic term, an analytical solution can be directly obtained. One should also notice that the stiffness of the system is modified by the damper stiffness and the damper global effect acts on both the damping coefficient and the stiffness.

In this work, railways bridge moving traffic loads used are those defined by Eurocode 1. There are two types of train loads that should be considered depending on the span length. As the span length used in this study is greater than 7 $\mathrm{m}$, only the 10 High-Speed Load Models (HSLMs) denoted HSLM-A where $A=1, \ldots, 10$ referring to the train model are applied [1].

\subsection{Equivalent viscous damping}

Viscous dampers made of viscoelastic material layers bonded to steel plates dissipate energy through shear deformation. The equation of motion of this device contains a nonlinear component which has been shown to be well described by fractional derivative operators. Considering the first mode of vibration, the equation of motion of the system can be expressed as

$$
M \ddot{q}_{b}(t)+C D^{\alpha}\left[q_{b}(t)\right]+K_{e q} q_{b}(t)=f(t)
$$

with $K_{e q}=K+P^{T} K_{D} P$ is the modified stiffness.

Eq. (6) has been linearized by adjusting the damping term according to the following linear form

$$
M \ddot{q}_{b}(t)+C_{e q} \dot{q}_{b}(t)+K_{e q} q_{b}(t)=f(t)
$$

where $C_{e q}$ is the equivalent constant damping coefficient.

The issue of replacing the dissipated energy associated to a nonlinear damper by that of an equivalent linear damper when the excitation is periodic has been studied in [21]. This enables to state the equivalence of dissipated energy while providing the possibility of replacing the nonlinear Eq. (4) by a linear one which can then be integrated by using simple analytical approaches. This has a considerable numerical advantage in practice when dealing with multiple loading cases as those occurring in the case of high speed train bridges which are periodic of nature. According to [21], the equivalent viscous damping coefficient can be calculated as follows

$$
\begin{gathered}
C_{e q}=\frac{C}{2} \Omega^{\alpha-1} \frac{\sin (1-\alpha) \pi}{\sin \left(\frac{1-\alpha}{2}\right) \pi}=C \Omega^{\alpha-1} \sin (\pi \alpha / 2) \\
\text { with } C=\frac{G_{C} A}{h_{V E D} \omega_{b}} \sum_{i=1}^{N_{D}}\left[\varphi_{1}\left(x_{i}, \theta_{i}\right)\right]^{2}
\end{gathered}
$$

and where $\Omega$ is the excitation frequency.

It can be deduced from Eq. (8) that the total damping ratio coefficient is expressed by the relation:

$$
\xi=\xi_{b}+\frac{\Omega^{\alpha-1}}{2 m \omega_{b} L} \frac{\sin (1-\alpha) \pi}{\sin \left(\frac{1-\alpha}{2}\right) \pi} \frac{G_{C} A}{h_{V E D} \omega_{b}} \sum_{i=1}^{N_{d}}\left[\varphi_{1}\left(x_{i}, \theta_{i}\right)\right]^{2}
$$

where $\xi_{b}$ is the damping ratio of the beam as determined by Eurocode $1[1]$ as a function of the beam length.

In the case of linear damping, $\alpha=1$ the following equation holds 


$$
\xi=\xi_{b}+\frac{1}{m \omega_{b} L} \frac{G_{C} A}{h_{V E D} \omega_{b}} \sum_{i=1}^{N_{d}}\left[\varphi_{1}\left(x_{i}, \theta_{i}\right)\right]^{2}
$$

From this linearization, Eq. (4) becomes linear and below we use the Duhamel's integral for solving the equation of motion of the bridge retrofitted by inclined viscoelastic dampers.

The Duhamel representation can be also used to determine the resonance speed. This yields the formula of Xia et al. [22] which writes: $v_{\text {crit }}=\omega_{b} D / 2 \pi$ where $D$ is the coach length as specified for a given HSLM-A train model [1]. Below, the critical speed will be evaluated according to this formula.

VEDs configuration can be fixed by selecting the fixation points positions of dampers at the bottom of the bridge beam $x_{i}$ and by giving them some inclination $\theta_{i}$. Performance of VEDs will depend on these basic variables. So, an optimization problem can be stated in order to maximize the equivalent damping of the device as function of these parameters. One should also consider restraints on the geometric configuration of the VEDs with regards to the under bridge traffic and limitation due to the increased flexibility of the damper with its increased length. From a practical point of view, it could be difficult to place a damper as far as $2.5 \mathrm{~m}$ from the support which limits then the domain of $x_{i}$. Higher lengths of the damper can cause degradation of its performance. In order to have reasonable flexibility of the damper, the orientation angle $\theta$ should be higher than $\pi / 4$. This lower limit was adopted for dash-pot like dampers as indicated in [11].

\subsection{Efficiency indicators}

In order to investigate the influence of VEDS on the bridge beam dynamics, the following performance indicators are taken into account that give the relative variation of maximum acceleration and maximum displacement:

$$
\begin{aligned}
& J_{1}=1-\frac{\left(\ddot{q}_{b}^{\max }\right)_{\text {with VED }}}{\left(\ddot{q}_{b}^{\max }\right)_{\text {without VED }}} \\
& J_{2}=1-\frac{\left(q_{b}^{\max }\right)_{\text {with VED }}}{\left(q_{b}^{\max }\right)_{\text {without VED }}}
\end{aligned}
$$

where $q_{b}^{\max }$ is the beam maximum displacement and $\ddot{q}_{b}^{\max }$ is the maximum beam acceleration.

\section{RESULTS AND DISCUSSION}

\subsection{Simulation data and considered cases of study}

To assess the efficiency of VEDs in retrofitting railway bridges, two examples are considered below. They correspond both to the systems with isostatic simply supported pre-stressed reinforced concrete beams. The first example is a bridge that was studied in [9]. The second example was studied in [16]. The material and geometric properties of these two cases of study are listed in Table 1. One can notice that for bridge 1 , the beam weight is large because the cross section is large too. The beam is in fact designed to withstand the gravity and trains loads that act on a lengthy beam $L=30 \mathrm{~m}$. The most adverse moving train load as defined by Eurocode 1 depends on the actual bridge configuration. So, all the 10 HSLM-A loadings are to be tested with all possible circulating speeds up to resonance. It was found in [9] that the model HSLM-A8 is one of the most unfavorable as it yields the highest acceleration with the resonance speed $v_{1, \text { crit }}=286.5 \mathrm{~km} / \mathrm{h}$. Also, for the bridge 2, it was found that HSLM-A2 is the most adverse train loading with resonance speed $v_{2, c r i t}=220 \mathrm{~km} / \mathrm{h}$. This was verified in the actual study for bridge 2 , while for bridge 1 the most adverse load corresponds in the actual study to HSLM-A10. However, to make comparison, only HSLM-A8 will be considered for bridge 1 . The characteristics of these loadings are given in Table 2.

The following conditions were chosen for simulation of the two bridge cases without VEDs and when equipped with VEDs having optimal damping configuration. Temperature was fixed at $T=20{ }^{\circ} \mathrm{C}$ and the thickness of damper was fixed at $h_{V E D}=0.025 \mathrm{~m}$ according to Ref. [16]. Also, the VEDs used here are of the same type as considered in Ref. [16]. Their damping properties are determined according to Eq. (3) by using the coefficients $A_{0}, \alpha, \beta, \mu$, and $v$ that are given in Ref. [17], while the value of parameter $\eta=1.14$ for bridge 1 and $\eta=1.19$ for bridge 2 because of the frequency dependency. According to Refs. [17] and [16], the identified fractional derivative order is $\alpha=0.6$. The obtained properties of VEDs are then $G_{E}=2.152 \mathrm{MPa}$ and $G_{C}=2.444 \mathrm{MPa}$. The value of parameter $A$ was fixed at $A=0.12 \mathrm{~m}^{2}$ in Ref. [16], while in the present study, this parameter is kept variable in order to analyze its influence on the total number of dampers required to meet the Eurocode 1 recommendations in terms of acceleration and displacement limits. The value of the first mode natural

Table 1. Material and geometric beam properties as identified from the bridges studied in Refs. [9] and [16]

\begin{tabular}{cccccc}
\hline & $L[\mathrm{~m}]$ & $E I\left[\mathrm{GN} \cdot \mathrm{m}^{2}\right]$ & $m[\mathrm{~kg} / \mathrm{m}]$ & $\xi_{b}[\%]$ & $\omega_{b}[\mathrm{rad} / \mathrm{s}]$ \\
\hline $\begin{array}{c}\text { Bridge } \\
1[9]\end{array}$ & 30 & 83.8 & 25,000 & 1 & 20 \\
$\begin{array}{c}\text { Bridge } \\
2\end{array}$ & 9.70 & 5.72 & 9754 & 2 & 80.42 \\
{$[16]$} & & & & & \\
\hline
\end{tabular}

Table 2. Characteristics of the HSLM-A8 and HSLM-A2 high-speed trains [1]

\begin{tabular}{lcccc}
\hline $\begin{array}{l}\text { Universal } \\
\text { train }\end{array}$ & $\begin{array}{r}\text { Number of } \\
\text { coaches N }\end{array}$ & $\begin{array}{r}\text { Coach } \\
\text { length D } \\
{[\mathrm{m}]}\end{array}$ & $\begin{array}{r}\text { Bogie axle } \\
\text { spacing d } \\
{[\mathrm{m}]}\end{array}$ & $\begin{array}{r}\text { Force } \\
\mathrm{F}\end{array}$ \\
\hline A8 & 12 & 25 & 2.5 & 190 \\
A2 & 17 & 19 & 3.5 & 200 \\
\hline
\end{tabular}


frequency $\omega_{b}$ depends on the considered bridge. It is used to calculate the total equivalent damping ratio from Eq. (10) and Eq. (11) where the value of $\xi_{b}$ is determined according to Eurocode 1 [1], see column 5 of Table 1.

As ballasted tracks are considered in this work, the acceleration magnitude given by the dynamic response should not exceed the threshold value of $3.5 \mathrm{~m} / \mathrm{s}^{2}$ as stated by Eurocode 1. The magnitude of displacement should also be kept less than $L / 600$ where $L$ is the length of the bridge in $m$. To satisfy these criteria, adding passive control through calibrated dampers is performed below.

Fig. 2 gives the acceleration as function of the HSLM-A train speed for various values of beam damping $\xi_{b}$ in the case without VEDs for both bridges. One can see that resonance speed coincides with that predicted by Xia et al. formula, and the acceleration meets the limit constraint stated by the Eurocode 1 [1] as the damping ratio increases.

\subsection{Determining optimal configuration of VEDs}

To find the optimal configuration of dampers for each bridge, the equivalent damping given by Eq. (10) and Eq. (11) is calculated as function of parameters $x_{i} \in[0 ; 2.5](\mathrm{m})$ and $\theta \in[\pi / 4 ; \pi / 2]$. The eccentricity was fixed at $e / L=0.05$ for bridge 1 and $e / L=0.0371$ for bridge 2 .

Fig. 3 gives the total damping ratio for the first mode of vibration as obtained by using the data given in Subsection 3.1 for each of the two bridges.

(a)

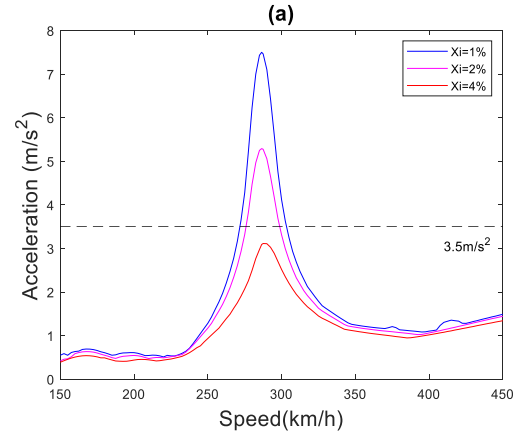

As shown in Fig. 3 the optimal configuration of VEDs corresponds to the positions and inclinations given in Table 3.

Since the maximum displacement and acceleration occur in the mid-span section, the time system response is evaluated by establishing for each bridge $x=L / 2$. The train loads considered correspond for Bridge 1 to HSLM-A8 while for bridge 2, the applied train load is the HSLM-A2. Simulation was conducted at the resonance speed which is $v_{1, \text { crit }}=286.5 \mathrm{~km} / \mathrm{h}$ for bridge 1 and $v_{2, \text { crit }}=220 \mathrm{~km} / \mathrm{h}$ for bridge 2. The two cases with and without VEDs are compared in order to evaluate the performance of dampers on attenuation of the system vibration. In order to satisfy the acceleration criterion, that is to say the acceleration is less than $3.5 \mathrm{~m} / \mathrm{s}^{2}$, the number of dampers was fixed at $N_{d}=4$ for either bridge 1 and bridge 2 . In fact, to avoid excitation of torsional modes, which requires a more sophisticated bridge modesling, the dampers should be symmetrically distributed

Table 3. Optimal configuration of VEDs as a function of the case of study, the data provided in Section 3.1 were used

\begin{tabular}{lccc}
\hline Bridge & $\begin{array}{r}\text { Eccentricity } \\
e[\mathrm{~m}]\end{array}$ & $\begin{array}{r}\text { Damper fixation } \\
\text { position } x_{i}[\mathrm{~m}]\end{array}$ & $\begin{array}{r}\text { Damper } \\
\text { inclination } \\
{[\mathrm{rad}]}\end{array}$ \\
\hline 1 & 1.5 & 2.4 & 1.05 \\
2 & 0.36 & 0.776 & 1.13 \\
\hline
\end{tabular}

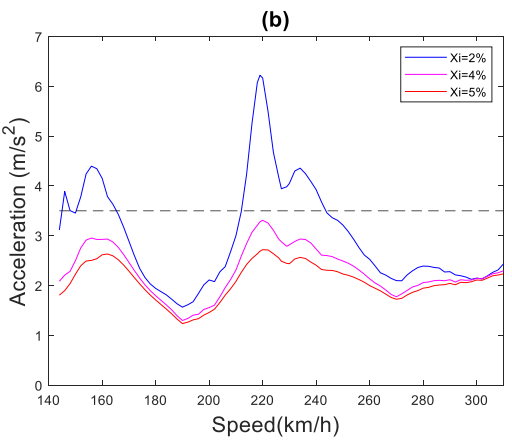

Fig. 2. Acceleration versus the speed for different values of damping beam coefficients without VEDs: (a) bridge 1; (b) bridge 2. The dotted line indicates the Eurocode 1 threshold $3.5 \mathrm{~m} / \mathrm{s}^{2}$.

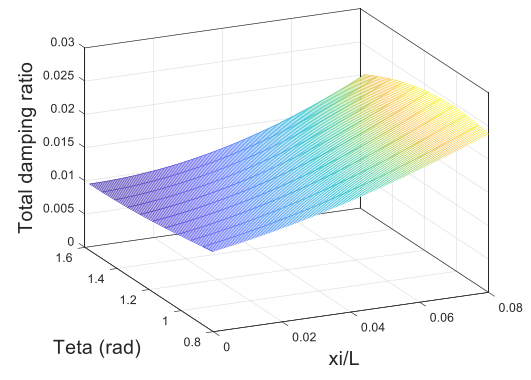

(a)

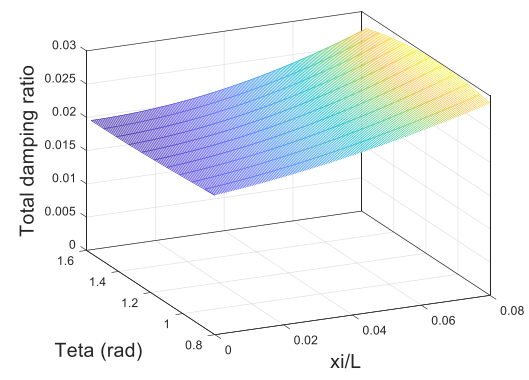

(b)

Fig. 3. Total damping ratio as function of the two dampers inclination and fixation position: (a) Bridge 1; (b) Bridge 2 
near the two abutments and the minimal configuration yields then at least four dampers.

Fig. 4 gives the time response in terms of acceleration and displacement of bridge 1 under the optimal configuration of dampers. Fig. 5 gives the time response in terms of acceleration and displacement of the bridge 2 while using optimal dampers configuration. Table 4 gives the maximum acceleration obtained at mid-span section for the two bridges.

Fig. 6 gives the amplitude response of bridge 1 as function of the HSLM-A8 train speed for the mid-span section. The two cases of optimal retrofitted bridge with 4 VEDs and without dampers are considered.

Fig. 7 gives the amplitude response of bridge 2 as function of the train speed of HSLM-A2 type for the mid-span section, and a comparison of the cases with optimal retrofitted bridge equipped with VEDs and without dampers is considered.

As shown in Fig. 4, for Bridge 1, the maximum dynamic acceleration and displacement are respectively $3.18 \mathrm{~m} / \mathrm{s}^{2}$ and $12.63 \mathrm{~mm}$ for the case with VEDs, while they are respectively $7.50 \mathrm{~m} / \mathrm{s}^{2}$ and $23.82 \mathrm{~mm}$ for the case without VEDs. The obtained total equivalent damping ratio is $\xi_{T}=3.86 \%$ and the criteria fixed by Eurocode 1 [1] are satisfied by retrofitted bridge with dampers, while they are
Table 4. Influence of the VEDs on the dynamic response of the beam at the mid-span section under the most adverse HSLM-A train load at the resonant speed for the two bridges: comparison between the cases with and without VEDs

\begin{tabular}{|c|c|c|c|}
\hline & & $\begin{array}{r}\text { Acceleration } \\
{\left[\mathrm{m} \cdot \mathrm{s}^{-2}\right]}\end{array}$ & $\begin{array}{r}\text { Displacement } \\
{[\mathrm{mm}]}\end{array}$ \\
\hline \multirow[t]{2}{*}{$\begin{array}{c}\text { Bridge } \\
1\end{array}$} & $\begin{array}{l}\text { Without } \\
\text { VEDs }\end{array}$ & 7.50 & 23.82 \\
\hline & With VEDs & 3.18 & 12.63 \\
\hline \multirow[t]{2}{*}{$\begin{array}{c}\text { Bridge } \\
2\end{array}$} & $\begin{array}{l}\text { Without } \\
\text { VEDs }\end{array}$ & 6.169 & 2.033 \\
\hline & With VEDs & 3.34 & 1.59 \\
\hline
\end{tabular}

not verified in the absence of VEDs. By means of implemented VEDs, the amplitude of vibration is reduced by an amount of $57.60 \%$ for the acceleration and $46.98 \%$ for the displacement.

Fig. 5, which corresponds to bridge 2, shows that the maximum acceleration and displacement have been reduced respectively from $6.169 \mathrm{~m} / \mathrm{s}^{2}$ and $2.03 \mathrm{~mm}$, before mounting VEDs, to the following values $3.34 \mathrm{~m} / \mathrm{s}^{2}$ and $1.59 \mathrm{~mm}$. The obtained total equivalent damping ratio is $\xi_{T}=3.89 \%$. The relative percentages of reduction for maximum acceleration and maximum displacement attain respectively 45.86 and $21.79 \%$. (a)

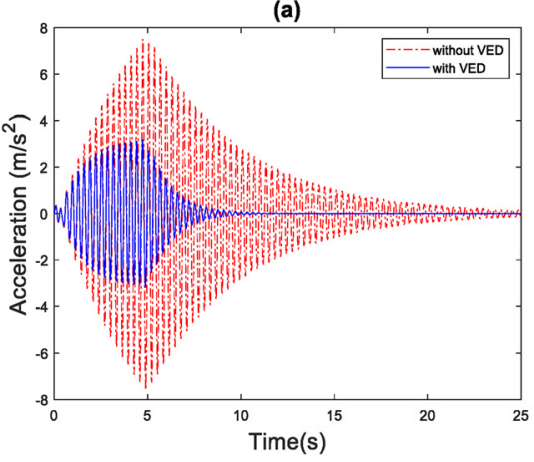

(b)

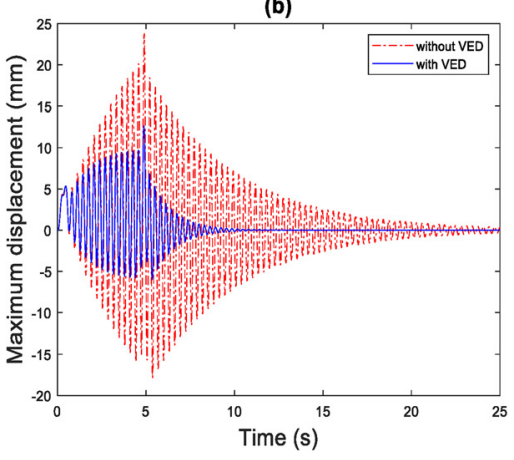

Fig. 4. Response of the mid-span section of bridge 1 under the HSLM-A8 train load at the resonant speed $v_{1, \text { crit }}=286.5 \mathrm{~km} / \mathrm{h}$; comparison between the cases with and without VEDs: (a) Acceleration and (b) Displacement

(a)

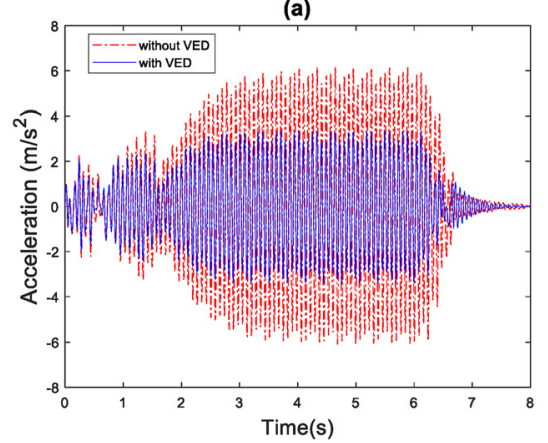

(b)

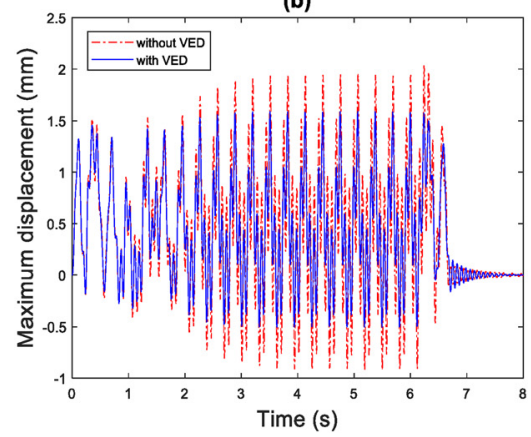

Fig. 5. Response of the mid-span section of bridge 2 under the HSLM-A2 train load at the resonant speed $v_{2, \text { crit }}=220 \mathrm{~km} / \mathrm{h}$; comparison between the cases with and without VEDs: (a) Acceleration and (b) Displacement 

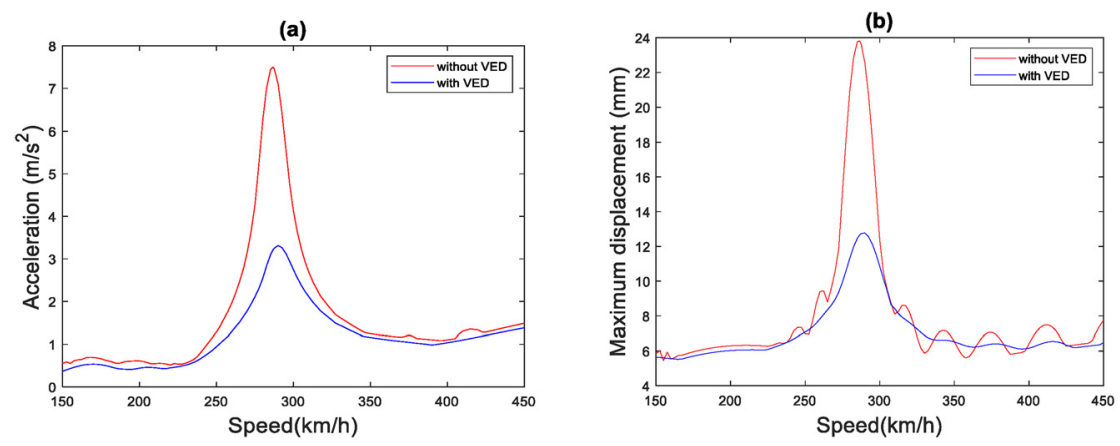

Fig. 6. Response of bridge 1 as function of the speed of HSLM-A8 train load for the mid-span section; comparison between the case of bridge retrofitted with 4 optimal VEDs and before retrofitting

(a)

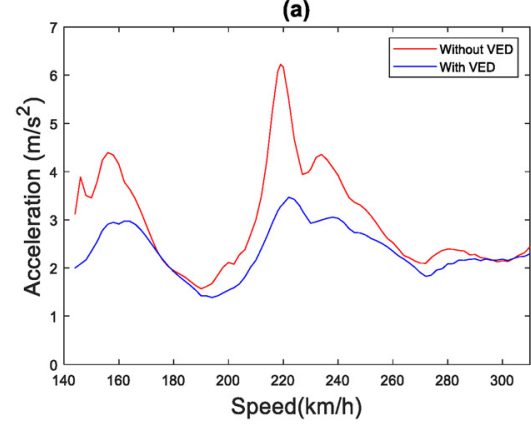

(b)

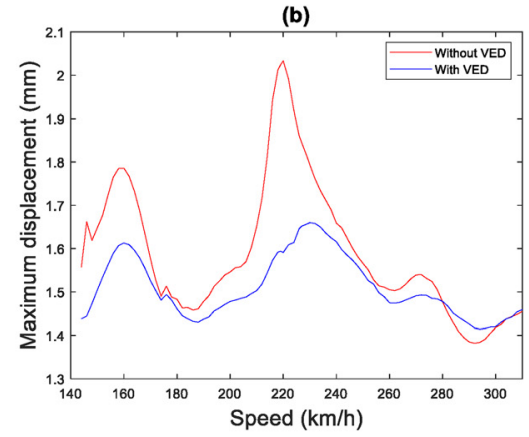

Fig. 7. Response of bridge 2 as function of the speed of HSLM-A2 train load for the mid-span section; comparison between the case of bridge retrofitted with 4 optimal VEDs and before retrofitting

Fig. 6 shows that the dynamic response of the bridge 1 in terms of acceleration and displacement reduces by using $N_{d}=4$ dampers and $A=0.12 \mathrm{~m}^{2}$ to the required limit as fixed by Eurocode 1. While the dynamic response exceeds largely these limits in the case without VEDs.

Fig. 7 shows that that the dynamic response of the bridge 2 is acceptable with reference to Eurocode 1 when $N_{d}=4$ and $A=0.12 \mathrm{~m}^{2}$. On the opposite, the dynamic response exceeds these limits in the case without VEDs.

It should be noticed that comparing the acceleration and displacement response as given in Figs. 6 and 7 shows coherence rather for the case without VEDs as the system is linear and damping is small. One can see that the coherence relationship $a_{\max }=-\omega_{b}^{2} d_{\max }$ is almost fulfilled. However, for the case with VEDs, the system is nonlinear with high damping and coherence between acceleration and displacement is lost.

\subsection{Comparison of the performance of the VEDs damping system with those studied in literature}

To evaluate performance of the VEDs based system for bridge retrofitting with those considered in the literature $[9,16]$, Table 5 summarizes the main characteristics of the various damping systems. Both of the studies performed in $[9,16]$ consider an auxiliary beam to enable mounting dampers at the mid-span section of the bridge. While in the actual study, no auxiliary beam is required as the VEDs are mounted directly

Table 5. Characteristics of damping systems as proposed in Refs. $[9,16]$ and comparison with the VEDs based solution considered in the actual study

\begin{tabular}{|c|c|c|c|c|c|}
\hline & \multirow[b]{2}{*}{$\begin{array}{l}\text { Damping } \\
\text { system }\end{array}$} & \multirow[b]{2}{*}{$\begin{array}{r}\text { Number of } \\
\text { dampers }\end{array}$} & \multirow[b]{2}{*}{$\begin{array}{l}\text { Total equivalent damping } \\
\text { coefficient } C_{D}[\mathrm{kN} \mathrm{s} / \mathrm{m}]\end{array}$} & \multicolumn{2}{|c|}{ Characteristics of the secondary beam } \\
\hline & & & & $\begin{array}{r}\text { Section area } \\
{\left[\mathrm{m}^{2}\right]}\end{array}$ & $\begin{array}{r}\text { Moment of inertia } \\
{\left[\mathrm{m}^{4}\right]}\end{array}$ \\
\hline \multirow{2}{*}{$\begin{array}{l}\text { Bridge } 1 \text { (Long } \\
\text { bridge) }\end{array}$} & Luu et al. [9] & 1 & 852 & 0.27 & 0.0833 \\
\hline & Actual study & 4 & 434.2 & 0 & 0 \\
\hline \multirow[t]{2}{*}{$\begin{array}{l}\text { Bridge } 2 \text { (Short } \\
\text { bridge) }\end{array}$} & $\begin{array}{l}\text { Moliner et al. } \\
\text { [16] }\end{array}$ & 2 & 418.5 & 0.178 & 0.03 \\
\hline & Actual study & 4 & 145 & 0 & 0 \\
\hline
\end{tabular}


Table 6. Maximum acceleration in $\left(\mathrm{m} / \mathrm{s}^{2}\right)$ at the mid-span section of the bridge as determined by considering the HSLM train load and the associated critical speed; comparison between retrofitted bridges and bridges before retrofitting $A=0.12 \mathrm{~m}^{2}$

\begin{tabular}{|c|c|c|c|c|}
\hline \multirow[b]{2}{*}{$\begin{array}{l}\text { HSLM } \\
\text { train } \\
\text { load }\end{array}$} & \multicolumn{3}{|c|}{ Bridge 1} & \multirow{2}{*}{$\begin{array}{r}\text { Bridge } 2 \\
\text { Optimally } \\
\text { retrofitted } \\
\text { with } \\
\text { VEDs } \\
{\left[N_{d}=4\right]}\end{array}$} \\
\hline & $\begin{array}{l}\text { Before } \\
\text { retrofitting }\end{array}$ & $\begin{array}{r}\text { Optimally } \\
\text { retrofitted } \\
\text { with VEDs } \\
{\left[N_{d}=4\right]}\end{array}$ & $\begin{array}{r}\text { Before } \\
\text { retrofitting }\end{array}$ & \\
\hline A1 & 3.39 & 1.15 & 2.76 & 2.24 \\
\hline A2 & 1.80 & 0.71 & 6.17 & 3.34 \\
\hline A3 & 0.52 & 0.45 & 2.83 & 1.83 \\
\hline A4 & 1.77 & 0.62 & 2.37 & 1.76 \\
\hline A5 & 3.18 & 1.13 & 3.24 & 2.03 \\
\hline A6 & 4.75 & 1.84 & 3.23 & 2.09 \\
\hline A7 & 6.56 & 2.63 & 2.88 & 1.94 \\
\hline A8 & 7.50 & 3.18 & 2.76 & 1.87 \\
\hline A9 & 9.43 & 4.24 & 3.12 & 1.95 \\
\hline A10 & 11.05 & 5.09 & 3.75 & 2.50 \\
\hline
\end{tabular}

on the bridge deck. Column 4 of Table 5 gives the total equivalent damping which is evaluated by multiplying the number of dampers used by the damping of a single damper.

One can notice that using VEDs which orientation is optimally determined and that are fixed at the proximity of abutments appears to be more effective than the system with an auxiliary beam coupled to the bridge beam by vertical dampers. Only 4 VEDs are required to obtain a dynamic response within the comfort margins fixed by Eurocode 1. With the actual solution based on VEDs, the total equivalent damping coefficient $C_{D}$ is almost equal to half of that required by the systems proposed in Refs. $[9,16]$. This is because of the beneficial effect due to both eccentricity and the damper inclination as shown by Eq. (10) where the modes are found to be sensitive to eccentricity and inclination according to Eq. (5d).

Here, only HSLM-A8 for bridge 1 and HSLM-A2 for bridge 2 were considered in order to make comparison with published results in the literature. Table 6 gives for the optimal damping system characteristics the maximum acceleration as function of the HSLM-A train load type.

Table 6 shows that for bridge 1, the train load HSLMA10 is the most unfavorable and that using retrofitting based on HSLM-A8 is not effective for the train loads HSLM-A9 and HSLM-A10 are not conform. On the contrary, for bridge 2 all the HSLM train loads pass after retrofitting which was performed according to HSLM-A2, the most unfavorable loading before retrofitting.

\subsection{The dynamic performance of the VEDs as function of temperature, shear area, and the number of dampers}

In this subsection, the influence on the dynamic performance of the VEDs parameters: temperature, shear area, and the number of dampers is studied. One of the important issues to decide on at the design stage is relative to the best shear area of dampers. Even if normally one expects that the performance of the VEDs should increase proportionally with increasing shear area Aof the dampers, its direct influence on the maximum acceleration and displacement is to be evaluated in order to determine optimally the required number of dampers to be installed, which should preferably be, as mentioned above, a multiple of number 4 . Temperature has also an influence on the results as stated by Eq. (3), but is this influence really significant in the range of common ambient variations of temperature?

Figs. 8 and 9 present, respectively for bridge 1 and bridge 2 , the results of a parametric study with regards to the influence of temperature and shear area on the maximum acceleration and displacement. For bridge 1, the train load is the HSLM-A8 with the critical speed $v_{1, \text { crit }}=286.5 \mathrm{~km} / \mathrm{h}$ and for bridge 2 the train load is the HSLM-A2 having the critical speed $v_{2, \text { crit }}=220 \mathrm{~km} / \mathrm{h}$.

Tables 7 and 8 present in the same conditions, respectively for bridge 1 and bridge 2, a parametric study about the influence of shear area and the number of VEDs on the maximum acceleration.
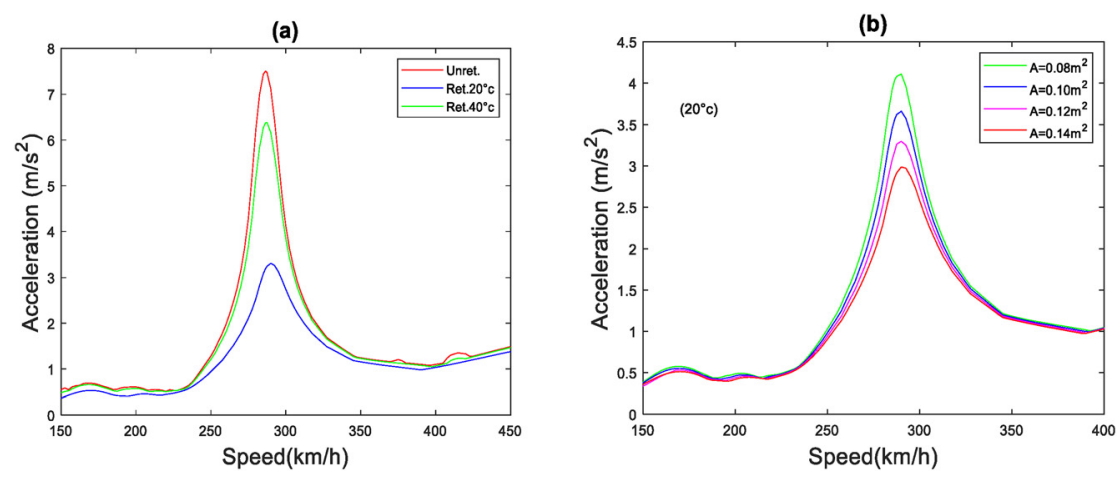

Fig. 8. Maximum vertical acceleration for retrofitted bridge 1 at the mid-span section as function of the speed of HSLM-A8 train load: (a) Effect of temperature variation $\left(N_{d}=4\right.$ and $A=0.12 \mathrm{~m}^{2}$ ), (b) Effect of shear area of the VEDs 
(a)

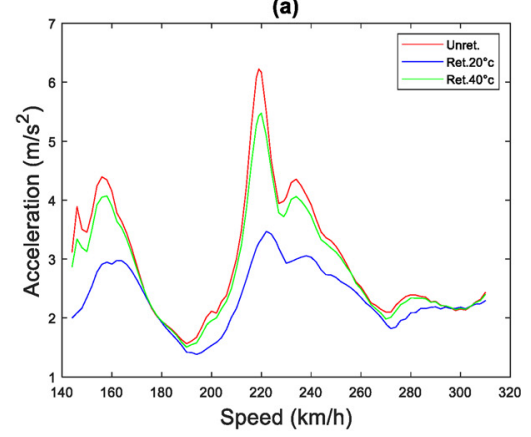

(b)

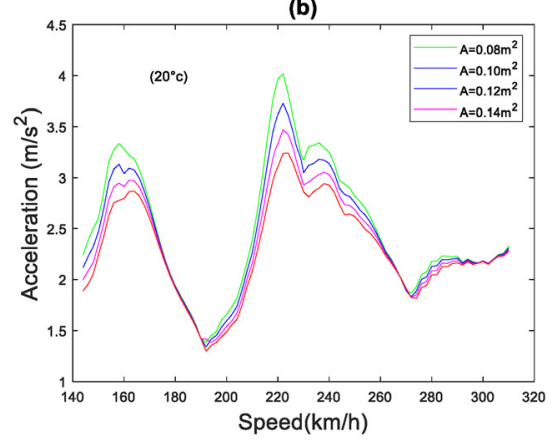

Fig. 9. Maximum vertical acceleration for retrofitted bridge 2 at the mid-span section as function of the speed of HSLM-A2 train load: (a) Effect of temperature variation $\left(N_{d}=4\right.$ and $\left.A=0.12 \mathrm{~m}^{2}\right)$ and (b) Effect of shear area of the VEDs

Table 7. Influence of the shear area of damper on the maximum acceleration in $\left(\mathrm{m} / \mathrm{s}^{2}\right)$ of the mid-span section of bridge 1 under the

HSLM-A8 train load at the critical speed $v_{1, \text { crit }}=286.5 \mathrm{~km} / \mathrm{h}$; temperature is fixed at $T=20^{\circ} \mathrm{C}$

\begin{tabular}{lcc}
\hline$N_{d} \mathrm{~A}\left[\mathrm{~m}^{2}\right]$ & 4 & 8 \\
\hline 0 & 7.50 & 7.50 \\
0.06 & 4.64 & 3.18 \\
0.08 & 4.04 & 2.60 \\
0.10 & 3.57 & 2.19 \\
0.12 & 3.18 & 1.90 \\
0.14 & 2.86 & 1.68 \\
\hline
\end{tabular}

Table 8. Influence of the shear area on the maximum acceleration in $\left(\mathrm{m} / \mathrm{s}^{2}\right)$ of the mid-span section of bridge 2 under the HSLM-A2 train load at the critical speed $v_{2, \text { crit }}=220 \mathrm{~km} / \mathrm{h}$; temperature is fixed at $T=20^{\circ} \mathrm{C}$

\begin{tabular}{lcc}
\hline$N_{d} \mathrm{~A}\left[\mathrm{~m}^{2}\right]$ & 4 & 8 \\
\hline 0 & 6.17 & 6.17 \\
0.06 & 4.38 & 3.34 \\
0.08 & 3.96 & 2.91 \\
0.10 & 3.62 & 2.59 \\
0.12 & 3.34 & 2.35 \\
0.14 & 3.11 & 2.15 \\
\hline
\end{tabular}

Fig. 10 gives the variations of the damping efficiency indicators as function of the shear area for the two bridges by fixing the number of VEDs at $N_{d}=4$.

Tables 7 and 8 show that different combinations of shear area and the number of dampers can be used to satisfy the Eurocode 1 criterion on acceleration. Considering bridge 1, 4 VEDs with $A=0.12 \mathrm{~m}^{2}$ or 8 VEDs with $A=0.06 \mathrm{~m}^{2}$ are sufficient to obtain the maximum acceleration less than $3.5 \mathrm{~m} / \mathrm{s}^{2}$ for temperature $T=20^{\circ} \mathrm{C}$. The same remark holds for bridge 2 . The solution with 4 VEDs having $A=0.12 \mathrm{~m}^{2}$ is more interesting than that with $8 \mathrm{VEDs}$ as the cost of devices and mounting is lower.

As stated by Eq. (3), the energy absorbing capacity of viscoelastic material decreases as a result of rising ambient temperature. Figs. 8a and 9a confirm this fact and show that the effect of temperature is important. The dynamic response in terms of acceleration increases for bridge 1 from $3.18 \mathrm{~m} / \mathrm{s}^{2}$ at $20^{\circ} \mathrm{C}$ to $6.37 \mathrm{~m} / \mathrm{s}^{2}$ at $40^{\circ} \mathrm{C}$. The maximum acceleration increases as function of ambient temperature. One should then consider the expected working temperature in order to size the VEDs accordingly. Figs. 8a and 9a show that the effect of shear area is proportional.

It should be noted that as the VED device contains an elastic part, its elastic rigidity modifies the fundamental (a)

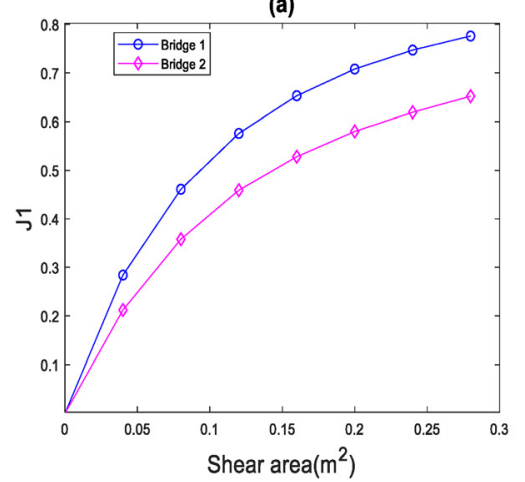

(b)

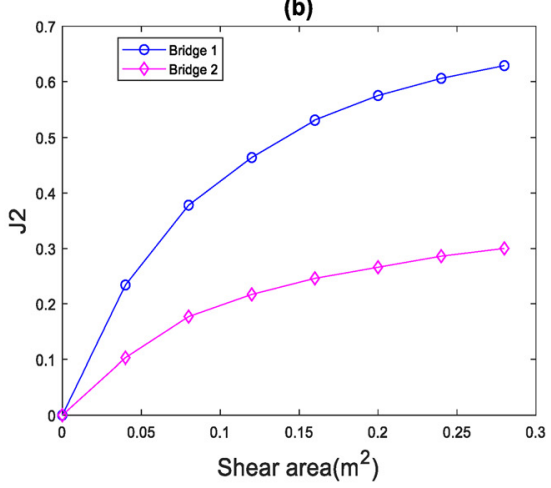

Fig. 10. Comparison of damping efficiency indicators as function of the shear area of the VEDs for the two bridges: (a) Acceleration efficiency indicator and (b) Displacement efficiency indicator 
frequency of the bridge. However, this change remains small. For instance, in the case of bridge 1, the critical speed passes from $v_{1, \text { crit }}=286.5$ to $v_{1, \text { crit }}=289.8 \mathrm{~km} / \mathrm{h}$. Taking into account, this correction yields a maximum acceleration of $3.29 \mathrm{~m} / \mathrm{s}^{2}$ instead of $3.18 \mathrm{~m} / \mathrm{s}^{2}$, which was determined without taking into account the stiffness of dampers.

Fig. 10 enables to emphasize sensitivity to shear area of total damping of the system based on VEDs, which is a key design parameter. The acceleration and displacement criteria are both considered. Fig. 10 shows that the effect of shear area varies depending on the considered bridge. In both bridge cases, the damping efficiency increases more slowly as shear area increases. However, the efficiency increases more rapidly for bridge 1 than for bridge 2, which indicates that the damping system based on VEDs is more effective for the lengthier bridge.

\section{CONCLUSIONS}

In the present work, pre-stressed reinforced concrete bridges having the form of simply supported beams were studied under the action of circulating high-speed trains according to Eurocode 1 statements. Damping of the bridge was considered in order to avoid the occurrence of high accelerations and displacements at resonance critical speeds. A new damping system was proposed. It consists of nonlinear viscoelastic dampers installed between the bottom surface of the bridge beam and the abutments without using any auxiliary beam. Using a planar approximation of the problem, optimization of dampers configuration was conducted in terms of their inclination with respect to the horizontal plane and as function of the bridge characteristics. Then, the required number of dampers was determined. Through comparison with literature, the obtained results indicate that the proposed damping strategy is more efficient than those using an auxiliary beam as the equivalent damping coefficient was found to be about half of that needed for the previous damping systems.

\section{REFERENCES}

[1] European Committee for Standardization, Basis of Structural Design - Annex A2: Application for Bridges, Final PT Draft EN 1990 - pr Annex A2, 2002.

[2] H. C. Kwon, M. C. Kim, and I. W. Lee, "Vibration control of bridges under moving loads," Comput. Struct., vol. 66, pp. 473-480, 1998.

[3] J. F. Wang, C. C. Lin, and B. L. Chen, "Vibration suppression for high-speed railway bridges using tuned mass dampers," Int. J. Solid Struct., vol. 40, pp. 465-491, 2003.

[4] M. Luu, V. Zabel, and C. Konke, "An optimization method of multi-resonant response of high-speed train bridges using TMDs," Finite Elem. Anal. Des., vol. 53, pp. 13-23, 2012.
[5] F. Samani and F. Pellicano, "Vibration reduction on beams subjected to moving loads using linear and nonlinear dynamic absorbers," J. Sound Vib., vol. 325, pp. 742-754, 2009.

[6] P. Museros and M. D. Martínez-Rodrigo, "Vibration control of simple supported beams under moving loads using fluid viscous dampers," J. Sound Vib., vol. 300, pp. 292-315, 2007.

[7] M. D. Martínez-Rodrigo, J. Lavado, and P. Museros, "Dynamic performance of existing high-speed railway bridges under resonant conditions retrofitted with fluid viscous dampers," Eng. Struct., vol. 32, pp. 808-828, 2010.

[8] M. D. Martínez-Rodrigo and P. Museros, "Optimal design of passive viscous dampers for controlling the resonant response of orthotropic plates under high-speed moving loads," J. Sound Vib., vol. 330, pp. 1328-1351, 2011.

[9] M. Luu, M. D. Martínez-Rodrigo, V. Zabel, and C. Könke, "Ho optimization of fluid viscous dampers for reducing vibrations of high-speed railway bridges," J. Sound Vib., vol. 333, pp. 24212442, 2014.

[10] J. Lavado, A. Domenenech, and M. D. Martinez-Rodrigo, "Dynamic performance of existing high-speed railway bridges under resonant conditions following a retrofit with fluid viscous dampers supported on clamped auxiliary beams," Eng. Struct., vol. 59, pp. 355-374, 2014.

[11] S. Raderstrom, M. U-Kaustell, A. Andersson, V. Tell, and R. Karoumi, "Application of fluid viscous dampers to mitigate vibrations of high-speed railway bridges," Int. J. Rail Transport., vol. 5, pp. 47-62, 2016.

[12] M. Muzaffer, A. Ulu, P. Mahmut, and E. Y. Murat, Vibration mitigation of railway bridge using magnetorheological damper, Modern Railway Engineering, Chapter2. Intech, 2018.

[13] P. Mahmoodi, L. E. Robertson, M. Yontar, C. Moy, and L. Feld, "Performance of viscoelastic dampers in World Trade Center towers," In: Proc. Structures Congress, Orlando, Florida, pp. 632644, 1987.

[14] J. F. Choo, H. M. Koh, S. C. Kang, and B. S. Kim, Vibration Control of Long-span High-speed Railway Bridges Under Periodic Moving Loading Using Viscoelastic Dampers, Structures for Highspeed Railway Transportation, Antwerp (Belgium): International Association for Bridge and Structural Engineering, 2003.

[15] E. Moliner, P. Museros, and M. D. Martinez-Rodrigo, Vibration control of high-speed railway bridges using viscoelastic dampers modelled by means of fractional derivatives. In: Proceeding of the International Conference in Noise and Vibration Engineering, pp. 2867-2877, 2008.

[16] E. Moliner, P. Museros, and M. D. Martinez-Rodrigo, "Retrofit of existing railway bridges of short to medium spans for high-speed traffic using viscoelastic dampers," Eng. Struct., vol. 40, pp. 519528, 2012.

[17] C. S. Tsai and H. H. Lee, "Applications of viscoelastic dampers to high-rise building,” J. Struct. Eng., vol. 119, pp. 1222-1232, 1993.

[18] K. C. Chang, T. T. Soong, S.-T. Oh, and M.-L. Lai, "Effect of temperature on viscoelastic ally damped structure," J. Struct. Eng., ASCE, vol. 118, pp. 1955-1973, 1992.

[19] K. L. Shen and T. T. Soong, "Modelling of viscoelastic dampers for structural applications," J. Eng. Mech., vol. 121, pp. 694-701, 1995. 
[20] R. Lewandowski and Z. Pawlak, "Dynamic analysis of frames with viscoelastic dampers modelled by rheological models with fractional derivatives," J. Sound Vib., vol. 330, pp. 923-936, 2011.

[21] J. Yuan, Y. Zhang, J. Liu, B. Shi, M. Gai, and S. Yang, "Mechanical energy and equivalent differential equations of motion for single- degree-of-freedom fractional oscillators," J. Sound Vib., vol. 9, pp. 192-203, 2017.

[22] H. Xia, Y. Zhang, and W. W. Guo, "Analysis of resonance mechanism and conditions of train bridge system," J. Sound Vib., vol. 297, pp. 810-822, 2005. 